\title{
Estimativa do potencial de rendimento por estrato do dossel da soja, em diferentes arranjos de plantas ${ }^{1}$
}

\author{
Yield potential estimated by soybean canopy stratum in response to plant arrangement
}

\author{
Lisandro Rambo ${ }^{2}$ José Antonio Costa ${ }^{3}$ João Leonardo Fernandes Pires ${ }^{4}$ \\ Geovano Parcianello ${ }^{5}$ Felipe Gutheil Ferreira ${ }^{6}$
}

\section{RESUMO}

$O$ potencial de rendimento da soja pode ser modificado pelo arranjo de plantas. Esta alteração pode resultar da contribuição diferenciada dos estratos do dossel para a determinação do potencial. $O$ experimento foi conduzido na Estação Experimental Agronômica da UFRGS, em Eldorado do Sul, RS, na estação de crescimento 2000/01, objetivando avaliar o potencial de rendimento em três estratos do dossel da soja em função da modificação do arranjo de plantas, em dois regimes hídricos. Utilizou-se a cultivar 'BRS 137', em semeadura direta. Os tratamentos constaram de níveis de irrigação (irrigado e não irrigado); espaçamentos entre linhas $(20$ e $40 \mathrm{~cm})$, e populações de plantas $(20,30$ e 40 plantas $\left.m^{-2}\right)$. Estimou-se o potencial de rendimento no início do enchimento de grãos (R5), admitindo-se que todas as flores se transformassem em legumes e que todos os legumes presentes neste estádio atingissem a maturação, formando grãos e contribuindo para o rendimento. $O$ dossel foi divido em três estratos, por dois planos paralelos ao solo, determinando-se o potencial de rendimento e o rendimento de grãos nas três seções do dossel. O tratamento irrigado apresentou maior potencial de rendimento da planta inteira em $R 5$ (14976 $\left.\mathrm{kg} \mathrm{ha}^{-1}\right)$ e rendimento de grãos em $R 8$ (maturação) que o não irrigado (12148 $\left.\mathrm{kg} \mathrm{ha}^{-1}\right)$, similar ao que ocorreu em todos os estratos do dossel. O arranjo de plantas com $20 \mathrm{~cm}$, independente da população, apresentou, em média, maior potencial de rendimento em $R 5(14970 \mathrm{~kg}$ $\left.\mathrm{ha}^{-1}\right)$ em relação ao arranjo com $40 \mathrm{~cm}\left(12154 \mathrm{~kg} \mathrm{ha}^{-1}\right)$, o que também foi verificado no estrato médio do dossel. Na maturação, o arranjo com espaçamento de $20 \mathrm{~cm}$, em combinação com a população de 20 plantas $\mathrm{m}^{-2}$, mostrou-se superior a $40 \mathrm{~cm}$ (6442 $\mathrm{kg} \mathrm{ha}^{-1}$ comparado com 4396 $\left.\mathrm{kg} \mathrm{ha}^{-1}\right)$, pelo maior rendimento nos estratos médio e inferior. Houve diminuição linear do potencial de rendimento em $R 5$ com o aumento da população de plantas, dentro do espaçamento de $20 \mathrm{~cm}$, explicado pelo comportamento similar nos estratos do dossel, obtendo-se a mesma resposta no rendimento em R8. Os estratos do dossel da soja contribuem diferentemente para o potencial de rendimento com a modificação do arranjo de plantas, decorrente da alteração do número de estruturas reprodutivas em $R 5$ e componentes do rendimento em $R 8$.

Palavras-chave: Glycine $\max ($ L.) Merrill, espaçamento entre linhas, estruturas reprodutivas, população de plantas.

\section{ABSTRACT}

The soybean yield potential can be modified by plant arrangement. This modification might be the result of the diferential contribution of the canopy strata for the potential determination. The experiment was conducted at the Agronomic Experimental Estation of the Universidade Federal do Rio Grande do Sul, in Eldorado do Sul, Rio Grande do Sul, Brazil, in the 2000/01 growing season. The objectives were to evaluate the yield potential by stratum of soybean canopy in different plant arrangement, under two water availability. The cultivar tested was BRS 137, in no-till planting. Water availability (irrigated an no irrigated), row spacing (20 and $40 \mathrm{~cm}$ ) and population levels (20, 30 and 40 plants $\left.\mathrm{m}^{-2}\right)$ were tested. The yield potential was estimated in the beginning of grain filling (R5). It was considered that all flowers and pods present at this stage were able to reach maturation, forming grains and contributing to yield. The canopy was divided in three strata by plans paralel to soil

${ }^{1}$ Extraído da dissertação de mestrado apresentada pelo primeiro autor ao Programa de Pós-graduação em Fitotecnia, Faculdade de agronomia (FA), Universidade Federal do Rio Grande do Sul (UFRGS), Porto Alegre, RS.

${ }^{2}$ Engenheiro Agrônomo MSc., Doutorando do Programa de Pós-graduação em Fitotecnia, FA/UFRGS. Departamento de Plantas de Lavoura. CP 776, 91501-970, Porto Alegre-RS. Bolsista do CNPq. E-mail: lisandro@vortex.ufrgs.br - Autor para correspondência. ${ }^{3}$ Engenheiro Agrônomo, PhD., Professor do Departamento de Plantas de Lavoura da FA/UFRGS. E-mail: jamc@.ufrgs.br ${ }^{4}$ Engenheiro Agrônomo, Doutor Pesquisador da Embrapa Trigo. E-mail: pires@cnpt.embrapa.br

${ }^{5}$ Engenheiro Agrônomo, MSc.

${ }^{6}$ Aluno do curso de Agronomia da UFRGS. Bolsista da FAPERGS. E-mail: ferreirafg@yahoo.com.br 
surface. The irrigated treatment (14976 $\left.\mathrm{k} \mathrm{ha}^{-1}\right)$ presented larger total plant yield potential and yield in $R 8$ (maturity) than without irrigation $\left(12148 \mathrm{~kg} \mathrm{ha}^{-1}\right)$, similar to what ocurred in all soybean canopy strata. The plant arrangement with $20 \mathrm{~cm}$ of row spacing, independent of population, presented, on the average, larger yield potential in R5 (14970 $\left.\mathrm{kg} \mathrm{ha}^{-1}\right)$ compared to $40 \mathrm{~cm}$ row spacing $\left(12154 \mathrm{~kg} \mathrm{ha}^{-1}\right)$. The same was also noticed at the medium soybean canopy stratum. At maturity the plant arrangement $20 \mathrm{~cm}$ of row spacing and population of 20 plants $\mathrm{m}^{-2}$ yielded more than $40 \mathrm{~cm}(6442 \mathrm{~kg}$ $\mathrm{ha}^{-1}$ compared to $\left.4396 \mathrm{~kg} \mathrm{ha}^{-1}\right)$, due to larger yield at the medium and botom stratum. There was a linear decrease in yield potential with increase of plant population, with row spacing reduction $(20 \mathrm{~cm})$, explained by the same behavior of the canopy strata. Similar response was obtained for yield in $R 8$. The soybean canopy strata contributed differently to yield potential with the plant arrangement modification, due to the diferential number of reproductives structures (R5) and yield components $(R 8)$ alteration.

Key words: Glycine max (L.) Merrill, row spacing, reproductives structures, plant population.

\section{INTRODUÇÃO}

O crescimento e desenvolvimento das culturas são modulados por fatores como radiação, água e temperatura (SINCLAIR, 1994). A influencia dos fatores que limitam o rendimento pode ser melhor compreendida se o potencial de rendimento for conhecido. A diferença entre o potencial de rendimento e o rendimento obtido dá a dimensão das perdas por estresses que afetam a cultura (EVANS, 1983). Em soja, estimativas do potencial de rendimento podem ser feitas durante a ontogenia por meio da quantificação das estruturas reprodutivas (flores e legumes), possibilitando verificar o efeito de práticas de manejo diferenciadas sobre a produção e fixação destas estruturas (PIRES et al., 2000). A estimativa do potencial de rendimento permite que se faça o planejamento da lavoura, podendo-se intervir nas safras vindouras pelo uso de práticas de manejo que visem amenizar a perda de potencial causada pelo estresses identificados nas safras anteriores.

Vários trabalhos têm sido feitos buscando estimar o potencial de rendimento da soja, sob diferentes condições de manejo. PIRES et al. (2000), em experimento sob semeadura direta e arranjo de plantas diferenciado, estimaram um potencial de rendimento médio de $15007 \mathrm{~kg} \mathrm{ha}^{-1}$ em R2 e de $10282 \mathrm{~kg}$ $\mathrm{ha}^{-1}$ em R5, sendo este influenciado pelo espaçamento entre linhas, no qual em $20 \mathrm{~cm}$ obtiveram $10962 \mathrm{~kg} \mathrm{ha}^{-1}$ e em $40 \mathrm{~cm} 9602 \mathrm{~kg} \mathrm{ha}^{-1}$. Nesta mesma linha, MAEHLER (2000), estimando o potencial de rendimento de duas cultivares de soja durante a ontogenia, em função do regime hídrico e arranjo de plantas, obteve maior potencial de rendimento nos estádios R2, R4 e R5 no tratamento irrigado do que no não irrigado, o que resultou em maior rendimento de grãos em R8 sob irrigação. Porém, este autor não observou diferença de potencial de rendimento entre espaçamentos de $20 \mathrm{~cm}$ e $40 \mathrm{~cm}$ entre linhas.

Nas lavouras de soja, têm sido normalmente utilizados arranjos de plantas que combinam espaçamentos entre linhas de $40 \mathrm{~cm}$ a $50 \mathrm{~cm}$ com população de 40 plantas $\mathrm{m}^{-2}$. A modificação destes arranjos de plantas afeta a competição intraespecífica. Portanto, o uso de espaçamentos estreitos $(20 \mathrm{~cm}) \mathrm{em}$ combinação com populações de plantas menores, poderiam levar a menores perdas no potencial de rendimento pela diminuição da competição entre plantas, sendo importante avaliar se isto ocorre em função da contribuição diferencial de cada estrato do dossel. O objetivo deste trabalho foi avaliar o potencial de rendimento em três estratos do dossel da soja em função da modificação do arranjo de plantas, em dois regimes hídricos.

\section{MATERIAL E MÉTODOS}

O experimento foi conduzido na Estação Experimental Agronômica da Universidade Federal do Rio Grande do Sul (EEA/UFRGS), localizada no município de Eldorado do Sul, região ecoclimática da Depressão Central do Estado do Rio Grande do Sul ( $30^{\circ} 05^{\prime} 27^{\prime \prime}$ de latitude sul e $51^{\circ} 40^{\prime} 18^{\prime \prime}$ de longitude oeste, com uma altitude média de $46 \mathrm{~m}$ ). O clima da região pertence à variedade específica $\mathrm{Cfa}$ da classificação climática de Köeppen, ou seja, subtropical úmido com verão quente (BERGAMASCHI \& GUADAGNIN, 1990). O solo da área experimental pertence à unidade de mapeamento São Jerônimo, classificado com Argissolo Vermelho Distrófico típico (EMBRAPA, 1999). A recomendação de adubação, baseada na análise de solo, indicou a quantidade de $50 \mathrm{~kg} \mathrm{ha}^{-1}$ de $\mathrm{P}_{2} \mathrm{O}_{5}$ e $50 \mathrm{~kg} \mathrm{ha}^{-1}$ de $\mathrm{K}_{2} \mathrm{O}$. Para suprir essa necessidade, foram aplicados $250 \mathrm{~kg} \mathrm{ha}^{-1}$ de adubo químico da fórmula 5-20-20.

O delineamento experimental foi o de blocos ao acaso com parcelas sub-subdivididas e quatro repetições. Os tratamentos constaram de dois regimes hídricos (irrigado e não irrigado), nas parcelas principais; dois espaçamentos entre linhas $(20$ e $40 \mathrm{~cm})$, nas subparcelas, e três populações de plantas $(20,30$ e 40 plantas. $\mathrm{m}^{-2}$ ), nas sub-subparcelas. As subsubparcelas tinham dimensão de 4 × $6 \mathrm{~m}$, considerandose como bordadura uma linha no espaçamento de $40 \mathrm{~cm}$ e duas linhas no de $20 \mathrm{~cm}$ em extremidade lateral e de $0,5 \mathrm{~m}$ em cada cabeceira, resultando numa área útil de $16 \mathrm{~m}^{2}$. 
Utilizou-se a cultivar BRS 137, de ciclo semiprecoce e hábito de crescimento determinado. $\mathrm{O}$ experimento foi instalado em semeadura direta. As sementes foram tratadas com fungicida [captan $(90 \mathrm{~g}$ de i.a. por $100 \mathrm{~kg}$ de semente)] e inoculadas com Bradyrhizobium japonicum em meio turfoso $(400 \mathrm{~g}$ de inoculante por $50 \mathrm{~kg}$ de semente). A semeadura foi realizada em 15/11/2000, sendo essa época recomendada preferencial para a região, utilizando semeadora de parcelas. Aos 15 dias após emergência, quando as plantas estavam no estádio V2 (COSTA \& MARCHEZAN, 1982) realizou-se o desbaste, ajustando-se para as populações desejadas. Mantevese o experimento livre de pragas e plantas daninhas. A irrigação foi feita por aspersão, de acordo com a umidade do solo, monitorada com tensiômetros, a 20 $\mathrm{cm}$ de profundidade, quando a tensão da água do solo ultrapassava o limite de -0,05 $\mathrm{MPa}$.

Para estimar o potencial de rendimento durante a ontogenia da soja, realizaram-se determinações em 10 plantas marcadas em sequiência na linha de cada sub-subparcela, fazendo-se avaliações sempre nas mesmas plantas durante os estádios R5 (início do enchimento de grãos) e R8 (maturação).

Quantificou-se o número de estruturas reprodutivas (flores + legumes) em R5, e em R8 determinaram-se os componentes, número de legumes com um, dois, três e sem grãos e o peso de 100 grãos de legumes com um, dois e três grãos, por estrato do dossel da soja. No estádio R5, a estratificação dossel foi efetuada levando-se em consideração a planta de maior estatura das dez plantas previamente marcadas em seqüência na linha, dividindo-se o dossel da soja a campo, em dois planos paralelos ao solo e efetuando-se a contagem das estruturas reprodutivas. No estádio R8, amostraram-se estas mesmas 10 plantas. Depois de coletadas, estas foram colocadas, lado a lado, sobre uma tábua graduada, em centímetros, simulando a disposição que encontravam-se no dossel no campo. Feito isto, foi efetuada a estratificação destas plantas em três planos paralelos, com base na planta de maior estatura.

A estratificação das plantas, com base na planta de maior estatura, visava dividir o dossel da soja em três seções de mesma altura. Para tanto, seccionou-se o caule, ramos e folhas em dois planos paralelos a $1 / 3$ e $2 / 3$ da estatura das plantas. Esta metodologia foi utilizada com o objetivo de representar melhor a estrutura do dossel da soja no campo, visando refletir de forma mais fidedigna a contribuição de cada estrato deste dossel, de acordo com a localização de suas estruturas vegetativas e reprodutivas, para o potencial de rendimento e rendimento de grãos.
O número de legumes com um, dois, três e sem grãos por estrato foi obtido pela contagem destes legumes na amostra de 10 plantas por parcela, previamente estratificadas, e depois transformados por $\mathrm{m}^{2}$ e percentagem. $O$ peso de 100 grãos por seção do dossel da soja foi realizado em amostra de 50 grãos, oriundo de legumes com um, dois e três grãos, separadamente.

Os dados obtidos em R8 foram utilizados para calcular o rendimento de grãos no final do ciclo e o potencial de rendimento em R5, quando aplicados aos valores de estruturas reprodutivas (flores + legumes) obtidas neste estádio. Esta estimativa é a representação do rendimento de grãos que seria obtido se as plantas conseguissem manter todas as estruturas reprodutivas presentes em R5, e se estas chegassem ao final do ciclo com a proporção de legumes sem grãos, com um, dois e três grãos e peso de 100 grãos daqueles obtidos em R8.

Os resultados obtidos foram submetidos à análise de variância (ANOVA), pelo teste F, sendo a diferença entre médias de tratamentos comparada pelo teste de Duncan a $5 \%$ de probabilidade de erro para os fatores irrigação e espaçamento entre linhas. O fator população de plantas foi comparado por análise de regressão.

\section{RESULTADOS E DISCUSSÃO}

O ano agrícola 2000/2001 foi de precipitação elevada, sendo que a precipitação média ocorrida foi $15 \mathrm{~mm}$ maior que a média de 20 anos para o mesmo período e região em que foi conduzido o experimento. Apesar disto, ocorreu deficiência hídrica no final do ciclo (estádio R6 - máximo volume de grãos) que, no tratamento irrigado, foi amenizada por três irrigações.

Considerando-se que todas as estruturas reprodutivas (flores e legumes) presentes no estádio R5 tivessem gerado legumes com um, dois, três e sem grãos, bem como grãos provenientes dos legumes férteis (um, dois e três grãos) com o peso de grão obtido no estádio R8, o potencial de rendimento médio estimado no estádio R5 foi de $13562 \mathrm{~kg} \mathrm{ha}^{-1}$ (Tabela 1).

$\mathrm{O}$ potencial de rendimento em R5 foi influenciado pelo regime hídrico e pelo arranjo de plantas (interação entre espaçamento e população), o que se refletiu no rendimento de grãos (R8). O potencial de rendimento estimado no estádio R5 foi maior no tratamento irrigado do que no não irrigado, nos três estratos do dossel. O rendimento de grãos foi incrementado significativamente pela irrigação no estrato médio (Tabela 1). O número de legumes com um, dois, três e sem grãos totais, em R8, não foi afetado 
Tabela 1 - Estimativa do potencial de rendimento (R5) e rendimento de grãos $\left(\mathrm{kg} \mathrm{ha}^{-1}\right)$ em R8 por estrato do dossel da cultivar de soja 'BRS 137' em dois regimes hídricos, na média de dois espaçamentos entre linhas e três populações de plantas. EEA/UFRGS, Eldorado do Sul (RS), 2000/2001

\begin{tabular}{lcccc}
\hline & \multicolumn{4}{c}{ Estádio fenológico } \\
\cline { 2 - 5 } $\begin{array}{l}\text { Estrato } \\
\text { dossel }\end{array}$ & do & \multicolumn{2}{c}{ R5 $^{*}$} & \multicolumn{2}{c}{ R8 } \\
\cline { 2 - 5 } & \multicolumn{2}{c}{ Regime hídrico } & \multicolumn{2}{c}{ Regime hídrico } \\
\cline { 2 - 5 } & Irrigado & Não irrigado & Irrigado & Não irrigado \\
\hline Superior & $4994 \mathrm{a}^{* *}$ & $4338 \mathrm{~b}$ & $1594 \mathrm{a}$ & $1412 \mathrm{a}$ \\
Médio & $7089 \mathrm{a}$ & $5635 \mathrm{~b}$ & $3400 \mathrm{a}$ & $2992 \mathrm{~b}$ \\
Inferior & $2893 \mathrm{a}$ & $2175 \mathrm{~b}$ & $536 \mathrm{a}$ & $494 \mathrm{a}$ \\
Planta inteira & $14976 \mathrm{a}$ & $12148 \mathrm{~b}$ & $5530 \mathrm{a}$ & $4898 \mathrm{~b}$ \\
Média & \multicolumn{2}{c}{13562} & \multicolumn{2}{c}{5214} \\
\hline
\end{tabular}

* R5 = início do enchimento de grãos; R8 = maturação.

** Médias não seguidas de mesma letra, na linha, dentro de cada estádio fenológico, diferem pelo teste de Duncan em nível de 5\% de probabilidade de erro. Coeficiente de variação da planta inteira para o regime hídrico $=3,162$ (R5) e 5,098 (R8). pelo regime hídrico. O fato da irrigação não ter influenciado estas variáveis deve-se principalmente à época que esta foi aplicada: estádio R6 = máximo volume de grãos. Neste período, o número de legumes está praticamente definido, sendo pouco afetado por deficiência hídrica.

O maior potencial de rendimento obtido no tratamento irrigado resultou do maior peso do grão (expresso em peso de 100 grãos) proporcionado pela irrigação nos legumes com um, dois e três grãos da planta inteira e nos três estratos do dossel (Tabela 2). $\mathrm{O}$ peso do grão e o número de legumes por planta aumentam em função da irrigação (THOMAS \& COSTA, 1994), sendo que o estresse hídrico ocorrido durante o enchimento de grãos reduz o peso do grão da soja (DESCLAUX et al., 2000). A falta de água durante o enchimento de grãos reduz o tamanho e peso do grão, devido à diminuição do suprimento de fotoassimilados produzidos pela planta e/ou inibição do metabolismo do próprio grão (SALINAS et al., 1996).

Em relação ao arranjo de plantas, houve interação entre o espaçamento entre linhas e população de plantas. Os maiores potenciais de rendimento estimados foram obtidos nos arranjos de plantas com

Tabela 2 - Peso de 100 grãos de legumes com um, dois e três grãos por estrato do dossel da soja, em dois regimes hídricos, na média de dois espaçamentos entre linhas e três populações de plantas; e número de legumes por $\mathrm{m}^{2}$ com um, dois, três e sem grãos por estrato do dossel da cultivar de soja 'BRS 137', em dois espaçamentos entre linhas, na população de $20 \mathrm{plantas}^{-2}$, na média de dois regimes hídricos. EEA/UFRGS, Eldorado do Sul, RS, 2000/2001

\begin{tabular}{|c|c|c|c|c|c|}
\hline & & \multicolumn{2}{|c|}{ Peso de 100 grãos (g) } & \multicolumn{2}{|c|}{ № de legumes $\mathrm{m}^{-2}$} \\
\hline \multicolumn{2}{|c|}{$\begin{array}{l}\text { Estrato do dossel (legumes com um, dois, três e } \\
\text { sem grãos) }\end{array}$} & \multicolumn{2}{|c|}{ Regime hídrico } & \multicolumn{2}{|c|}{ Espaçamento } \\
\hline & & Irrigado & Não irrigado & $20 \mathrm{~cm}$ & $40 \mathrm{~cm}$ \\
\hline \multirow{4}{*}{ Superior } & (sem grão) & - & - & $4,3 \mathrm{a}$ & $4,6 \mathrm{a}$ \\
\hline & (um grão) & $19,0 \mathrm{a}^{*}$ & $14,7 \mathrm{~b}$ & $64,4 \mathrm{a}$ & $34,5 \mathrm{~b}$ \\
\hline & (dois grãos) & $19,4 \mathrm{a}$ & $16,1 \mathrm{~b}$ & $248,3 \mathrm{a}$ & $171,0 \mathrm{~b}$ \\
\hline & (três grãos) & $19,5 \mathrm{a}$ & $17,7 \mathrm{~b}$ & $92,6 \mathrm{a}$ & $57,0 \mathrm{~b}$ \\
\hline \multirow{4}{*}{ Médio } & (sem grão) & - & - & $7,5 \mathrm{a}$ & $8,2 \mathrm{a}$ \\
\hline & (um grão) & $18,7 \mathrm{a}$ & $15,4 \mathrm{~b}$ & $97,5 \mathrm{a}$ & $60,1 \mathrm{~b}$ \\
\hline & (dois grãos) & $18,5 \mathrm{a}$ & $15,4 \mathrm{~b}$ & $364,2 \mathrm{a}$ & $223,7 \mathrm{~b}$ \\
\hline & (três grãos) & $18,1 \mathrm{a}$ & $15,1 \mathrm{~b}$ & 290,1 a & $178,2 \mathrm{~b}$ \\
\hline \multirow{3}{*}{ Inferior } & (sem grão) & - & - & $1,6 \mathrm{a}$ & $1,7 \mathrm{a}$ \\
\hline & (um grão) & $16,6 \mathrm{a}$ & $13,2 \mathrm{a}$ & $21,2 \mathrm{a}$ & $14,4 \mathrm{a}$ \\
\hline & (dois grãos) & $20,9 \mathrm{a}$ & $16,4 \mathrm{~b}$ & $83,4 \mathrm{a}$ & $56,8 \mathrm{~b}$ \\
\hline \multirow{6}{*}{ Planta inteira } & (três grãos) & $19,8 \mathrm{a}$ & $16,1 \mathrm{~b}$ & $66,9 \mathrm{a}$ & $41,3 \mathrm{~b}$ \\
\hline & (sem grão) & - & - & $13,4 \mathrm{a}$ & $14,5 \mathrm{a}$ \\
\hline & (um grão) & $18,1 \mathrm{a}$ & $14,4 \mathrm{~b}$ & $183,1 \mathrm{a}$ & $109,0 \mathrm{~b}$ \\
\hline & (dois grãos) & $19,6 \mathrm{a}$ & $16,0 \mathrm{~b}$ & $695,9 \mathrm{a}$ & $451,5 \mathrm{~b}$ \\
\hline & (três grãos) & $19,1 \mathrm{a}$ & $16,3 \mathrm{~b}$ & 449,6 a & $276,5 b$ \\
\hline & tal & - & - & $1342 \mathrm{a}$ & 852 b \\
\hline
\end{tabular}

*Médias não seguidas de mesma letra, na linha, dentro do fator regime hídrico e do fator espaçamento, diferem pelo teste de Duncan em nível de 5\% de probabilidade de erro. Coeficiente de variação da planta inteira para regime hídrico = 5,896 (um grão), 1,806 (dois grãos) e 2,884 (três grãos); para espaçamento entre linhas = 38,076 (sem grão), 12,652 (um grão), 5,627 (dois grãos) e 15,153 (três grãos). 
espaçamento de $20 \mathrm{~cm}$, independente da população de plantas. Isto ocorreu pelo maior potencial dos estratos médio e inferior na população de 20 plantas $\mathrm{m}^{-2}$ e estrato médio nas demais (Tabela 3 ). No que se refere ao rendimento de grãos, o arranjo de plantas de $20 \mathrm{~cm}$ de espaçamento entre linhas em combinação com a população de 20 plantas $\mathrm{m}^{-2}$ apresentou o melhor resultado, devido aos maiores rendimentos de grãos obtidos nos estratos médio e inferior do dossel. $\mathrm{O}$ potencial de rendimento em R5 aumentou linearmente, dentro do espaçamento de $20 \mathrm{~cm}$ com a diminuição da população de plantas, novamente em função dos estratos médio e inferior do dossel da soja. O mesmo foi observado com o rendimento de grãos em R8 (Figura 1).

O maior potencial de rendimento obtido com a redução do espaçamento entre linhas dentro de todos os níveis populacionais pode estar associado à menor da competição intraespecífica. A redução do espaçamento entre linhas, em uma mesma população de plantas, distribui melhor as plantas na área. Plantas da linha em espaçamento de $40 \mathrm{~cm}$ são dispostas na entrelinha, pois o espaçamento de $20 \mathrm{~cm}$ permite o dobro de linhas. Desta forma, reduz-se a competição intraespecífica, pela maior aproximação da eqüidistância entre as plantas dentro da mesma linha e com as plantas de outras linhas. Na mesma população de plantas, ocorre maior competição entre plantas, devido ao sombreamento, em espaçamentos largos, onde as plantas estão mais próximas na linha, do que em espaçamento estreitos. A redução do espaçamento entre linhas tem resultado em acréscimos no potencial de rendimento e no rendimento de grãos (UDOGUCHI \& MCCLOUD,1987; THOMAS et al., 1998; PIRES et al., 1998; PIRES et al., 2000), e estão associados a vários fatores, como o melhor uso da água devido ao sombreamento mais rápido do solo pelo dossel, melhor distribuição de raízes, redução da competição intraespecífica, maior habilidade na competição com plantas daninhas, exploração uniforme da fertilidade do solo, e maior e mais rápida intercepção da radiação solar.

O número de legumes com um, dois e três grãos totais foram afetados pela interação de

Tabela 3 - Número de estruturas reprodutivas e estimativa do potencial de rendimento de grãos (PR) em $\mathrm{R} 5^{*}$, e rendimento de grãos em $\mathrm{R} 8^{* *}$ por estrato do dossel da cultivar de soja 'BRS 137' em dois espaçamentos entre linhas e três populações de plantas, na média de dois regimes hídricos. EEA/UFRGS, Eldorado do Sul (RS), 2000/2001

\begin{tabular}{|c|c|c|c|c|c|c|}
\hline \multirow{4}{*}{ Estrato do dossel } & \multicolumn{6}{|c|}{ População (plantas $\mathrm{m}^{-2}$ ) } \\
\hline & \multicolumn{2}{|c|}{20} & \multicolumn{2}{|c|}{30} & \multicolumn{2}{|c|}{40} \\
\hline & \multicolumn{2}{|c|}{ Espaçamento } & \multicolumn{2}{|c|}{ Espaçamento } & \multicolumn{2}{|c|}{ Espaçamento } \\
\hline & $20 \mathrm{~cm}$ & $40 \mathrm{~cm}$ & $20 \mathrm{~cm}$ & $40 \mathrm{~cm}$ & $20 \mathrm{~cm}$ & $40 \mathrm{~cm}$ \\
\hline \multicolumn{7}{|c|}{ Número de estruturas reprodutivas $\left(\mathrm{n}^{\mathrm{o}}\right.$ de estruturas $\left.\mathrm{m}^{-2}\right)$} \\
\hline Superior & $1244 \mathrm{a}^{* * *}$ & 1016 a & 1309 a & $1193 \mathrm{a}$ & 1448 a & $1450 \mathrm{a}$ \\
\hline Médio & 2189 a & $1543 \mathrm{~b}$ & 1739 a & $1625 \mathrm{~b}$ & $1618 \mathrm{a}$ & $1429 \mathrm{~b}$ \\
\hline Inferior & 807 a & 572 a & $642 \mathrm{a}$ & 598 a & $600 \mathrm{a}$ & $527 \mathrm{a}$ \\
\hline Planta inteira & 4240 a & $3131 \mathrm{~b}$ & $3690 \mathrm{a}$ & $3416 \mathrm{~b}$ & 3666 a & $3406 \mathrm{~b}$ \\
\hline \multicolumn{7}{|c|}{ Estimativa do potencial de rendimento de grãos $\left(\mathrm{kg} \mathrm{ha}^{-1}\right)$} \\
\hline Superior & 4717 a & $3530 \mathrm{a}$ & 4818 a & $4312 \mathrm{a}$ & $5230 \mathrm{a}$ & $5390 \mathrm{a}$ \\
\hline Médio & 8815 a & $5408 \mathrm{~b}$ & 6539 a & 5996 b & $6153 \mathrm{a}$ & $5261 \mathrm{~b}$ \\
\hline Inferior & $3604 \mathrm{a}$ & $2164 \mathrm{~b}$ & $2608 \mathrm{a}$ & $2371 \mathrm{a}$ & $2428 \mathrm{a}$ & $2029 \mathrm{a}$ \\
\hline Planta inteira & $17136 \mathrm{a}$ & $11102 \mathrm{~b}$ & $13965 \mathrm{a}$ & $12679 \mathrm{~b}$ & $13811 \mathrm{a}$ & $12680 \mathrm{~b}$ \\
\hline \multicolumn{7}{|c|}{ Rendimento de grãos $\left(\mathrm{kg} \mathrm{ha}^{-1}\right)$} \\
\hline Superior & $1556 \mathrm{a}$ & $1405 \mathrm{a}$ & $1732 \mathrm{a}$ & 1418 a & 1648 a & $1260 \mathrm{a}$ \\
\hline Médio & $4153 \mathrm{a}$ & $2540 \mathrm{~b}$ & $3335 \mathrm{a}$ & 3055 a & 3070 a & $3022 \mathrm{a}$ \\
\hline Inferior & $733 \mathrm{a}$ & $451 \mathrm{~b}$ & $535 \mathrm{a}$ & $485 \mathrm{a}$ & $485 \mathrm{a}$ & 399 a \\
\hline Planta inteira & $6442 \mathrm{a}$ & $4396 \mathrm{~b}$ & $5602 \mathrm{a}$ & 4958 a & 5203 a & 4681 a \\
\hline
\end{tabular}

Ciência Rural, v.34, n.1, jan-fev, 2004. 


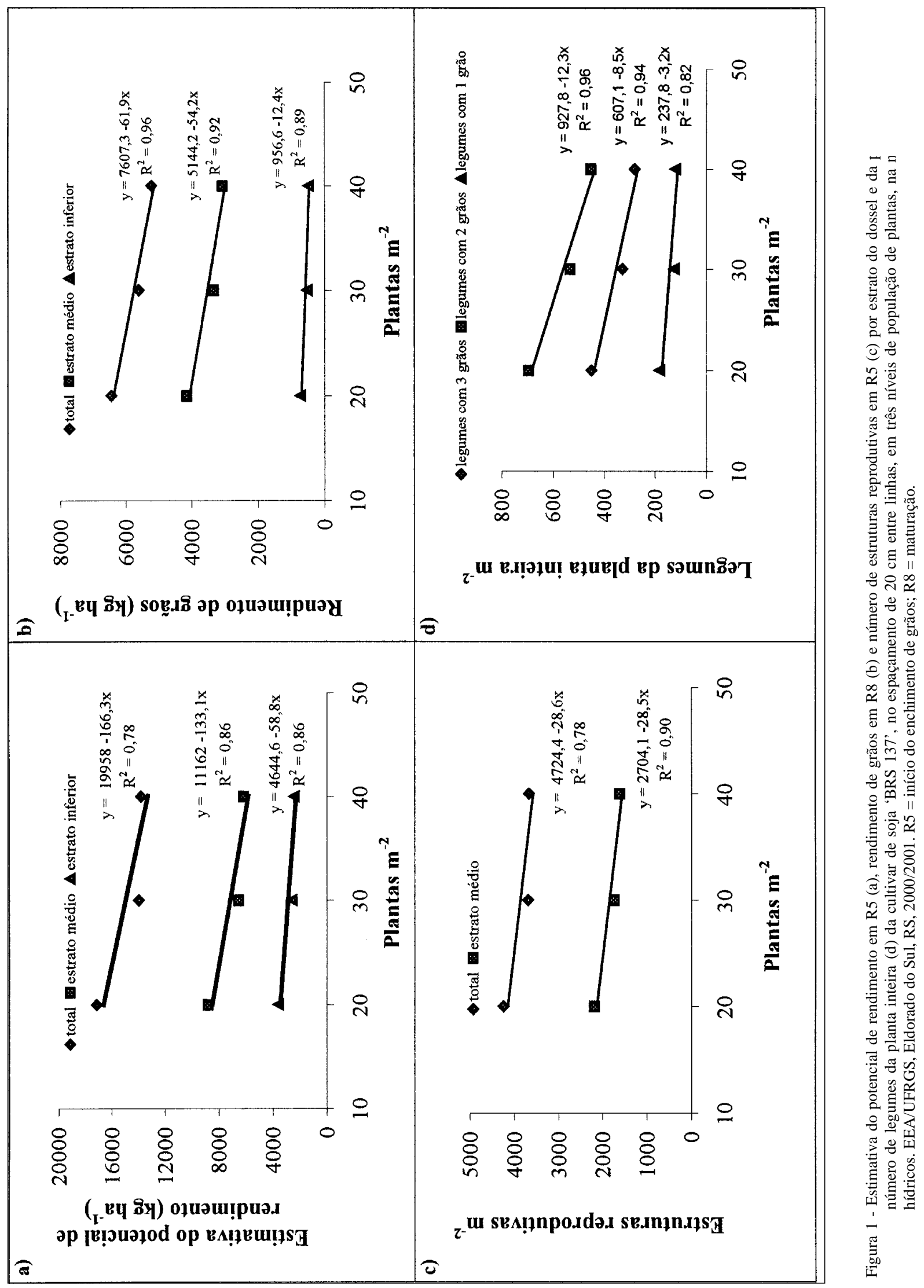

Ciência Rural, v.34, n.1, jan-fev, 2004. 
espaçamento entre linhas e população de plantas (Tabela 2 e Figura 1). O tratamento de 20 plantas $\mathrm{m}^{-2}$ com $20 \mathrm{~cm}$ de espaçamento apresentou maior número de legumes, nas três categorias, em relação ao arranjo utilizando $40 \mathrm{~cm}$, o que foi verificado em todos os estratos do dossel, com exceção do número de legumes com um grão do estrato inferior e sem grãos em que não houve diferença. Foi observado também que o número de legumes com um, dois e três grãos da planta inteira diminuiu linearmente com o aumento da população de plantas, que pode ser verificado em todos os estratos do dossel da soja, exceto o número de legumes com um grão do estrato inferior.

O número de legumes $\mathrm{m}^{-2}$ é o componente do rendimento mais variável com a modificação do arranjo de plantas, sofrendo as maiores modificações pela utilização de práticas de manejo, uma vez que o número de grãos por legume e o peso do grão são menos influenciados pelo ambiente (COOPERATIVE..., 1994). Aumentos no rendimento de grãos pela redução do espaçamento entre linhas têm sido obtidos, principalmente pela maior produção de legumes por área (UDOGUCHI \& MCCLOUND,1987; THOMAS et al., 1998)

$\mathrm{O}$ arranjo de plantas também influenciou o peso do grão (expresso pelo peso de 100 grãos) da soja. A combinação da população de 20 plantas $\mathrm{m}^{-2}$ com $20 \mathrm{~cm}$ de espaçamento entre linhas apresentou maior peso do grão dos legumes com um $(17,8 \mathrm{~g})$ e dois grãos $(19,2 \mathrm{~g})$ da planta inteira, em relação a $40 \mathrm{~cm}$ de espaçamento (legumes com um grão da planta inteira $=15,3 \mathrm{~g}$ e legumes com dois grãos da planta inteira $=$ $16,7 \mathrm{~g}$ ), sendo que este comportamento foi observado somente no estrato inferior com o peso do grão de legumes com dois grãos. Observou-se, ainda, diminuição linear do peso do grão de legumes com um e dois grãos da planta inteira com o aumento da população de plantas, dentro do espaçamento entre linhas de $20 \mathrm{~cm}$, o que ocorreu também no estrato inferior com o peso do grão de legumes com dois grãos.

Os estudos com arranjo de plantas geralmente não tem mostrado efeito no peso do grão da soja (UDOGUCHI \& MCCLOUND, 1987; THOMAS et al., 1998; PIRES et al., 1998; PIRES et al., 2000). No entanto, as respostas obtidas em relação a esta variável neste trabalho podem ter sido em função da grande amplitude dos arranjos de plantas utilizados, proporcionando uma maior variação na competição intraespecífica, que se refletiu também no peso do grão. Além disso, a decomposição do peso do grão por legumes com um, dois e três grãos possibilitou maior detalhamento do efeito compensatório que se observa em função da relação número de legumes/ peso do grão.
A quantificação do número de estruturas reprodutivas em R5 é importante para a determinação do potencial de rendimento da soja nos estádios reprodutivos. Estas são utilizadas no cálculo da estimativa do potencial de rendimento e têm alta correlação com o valor estimado (PIRES, 2002). Quando foram avaliadas as estruturas reprodutivas (flores e legumes) no estádio R5, verificou-se que o número destas foi influenciado pelo arranjo de plantas (Tabela 3 e Figura 1). O espaçamento de $20 \mathrm{~cm}$ apresentou maior número de estruturas reprodutivas nos três níveis populacionais, com aumento linear com a diminuição da população, o que foi igualmente observado no estrato médio do dossel da soja. Estes resultados ajudam a explicar as respostas obtidas pela estimativa do potencial de rendimento no dossel da soja em R5 quanto ao arranjo de plantas.

O método de estimativa do potencial de rendimento utilizado neste estudo simula melhor a realidade do que os métodos que consideram os fatores limitantes em níveis adequados, pois, em parte, leva em conta os efeitos destes fatores, por meio de sua interação na produção e fixação de estruturas reprodutivas (PIRES et al., 2000). No entanto, permite que o valor estimado seja obtido apenas após a colheita da soja, pois necessita de valores do estádio R8 que são usados para estimar o potencial de rendimento no estádio R5. Desta forma, os resultados obtidos poderão ser utilizados para o planejamento da próxima safra, buscando utilizar práticas de manejo que visem diminuir a perda do potencial de rendimento identificado na safra anterior. Esta metodologia necessita ser adaptada para que se possa estimar o potencial de rendimento sem os dados do estádio R8, possibilitando que o valor estimado do potencial de rendimento seja obtido já nos estádios reprodutivos iniciais (a partir de R1). Assim, será possível utilizar práticas de manejo que visem manter e/ou amenizar a perda do potencial de rendimento estimado no mesmo ciclo da soja.

\section{CONCLUSÕES}

Com a utilização do arranjo de plantas com $20 \mathrm{~cm}$ de espaçamento e a população de 20 plantas $\mathrm{m}^{-2}$ é possível reduzir a perda do potencial de rendimento a partir do estádio R5, resultando em maior rendimento de grãos em R8 em relação ao espaçamento de $40 \mathrm{~cm}$ e as demais populações de plantas (30 e 40 plantas $\mathrm{m}^{-2}$ );

Os estratos superior e médio do dossel da soja apresentam a maior contribuição para o potencial de rendimento e rendimento de grãos da soja, pela 
maior presença de estruturas reprodutivas (flores e legumes) em R5 e legumes por área em R8;

A irrigação, mesmo quando aplicada no final do ciclo, reduz a perda do potencial de rendimento da soja.

\section{REFERÊNCIASBIBLIOGRÁFICAS}

BERGAMASCHI, H.; GUADAGNIN, M.R. Agroclima da Estação Experimental Agronômica/UFRGS. Porto Alegre: Departamento de Plantas Forrageiras e Agrometeorologia da UFRGS, 1990. 60p.

COOPERATIVE EXTENSION SERVICE AMES. How a soybean plant develops. Ames: Iowa State University of Science and Technology, 1994. 20p.

COSTA, J.A.; MARCHEZAN, E. Características dos estádios de desenvolvimento da soja. Campinas : Fundação Cargil, 1982. 30p.

DESCLAUX, D.; HUYNH, T.; ROUMET, P. Identification of soybean plant characteristics that indicate the timing of drought stress. Crop Science, Madison, v.40, n.3., p.716722, mai-jun., 2000.

EMBRAPA. Centro Nacional de Pesquisas de Solos. Sistema Brasileiro de Classificação de Solos. Brasília : EMBRAPA, 1999. 412p.

EVANS, J.R. Nitrogen and photosynthesis in the flag leaf of wheat (Triticum aestivum L.). Plant Physiology, Rockville, v.72, n.2, p.297-302, jun, 1983.

MAEHLER, A.R. Crescimento e rendimento de duas cultivares de soja em resposta ao arranjo de plantas e regime hídrico. 2000. 108f. Dissertação (Mestrado em Fitotecnia) - Programa de Pós-graduação em Fitotecnia. Faculdade de Agronomia, Universidade Federal do Rio Grande do Sul.
PIRES, J.L.; COSTA, J.A.; THOMAS, A.L. Rendimento de grãos de soja influenciado pelo arranjo de plantas e níveis de adubação. Pesquisa Agropecuária Gaúcha, Porto Alegre, v.4, n.2, p.183-188, 1998.

PIRES, J.L.F. et al. Efeito de populações e espaçamentos sobre o potencial de rendimento da soja durante a ontogenia. Pesquisa Agropecuária Brasileira, Brasília, v.35, n.8, p.1541-1547, ago, 2000.

PIRES, J.L.F. Potencial de rendimento da soja durante a ontogenia e caracterização da variabilidade espacial e temporal da produção de grãos. 2002. 140f. Tese (Doutorado em Fitotecnia) - Programa de Pós-graduação em Fitotecnia. Faculdade de Agronomia, Universidade Federal do Rio Grande do Sul.

SALINAS, A.R. et al. Respuestas fisiológicas que caracterizan el comportamiento de diferentes cultivares de soja a la deficiência hídrica. Pesquisa Agropecuária Brasileira, Brasília, v.31, n.5, p.331-338, mai, 1996.

SINCLAIR, T.R. Limits to crop yield? In: BOOTE, K.J. (Ed.). Physiology and determination of crop yield. Madison : American Society of Agronomy/Crop Science Society of America/Soil Science Society of America, 1994. p.509-532.

THOMAS, A.L.; COSTA, J.A. Influência do déficit hídrico sobre o desenvolvimento e rendimento da soja. Pesquisa Agropecuária Brasileira, Brasília, v.29, n.9, p.1389-1396, set, 1994.

THOMAS, A.L.; COSTA, J.A.; PIRES, J.L. Rendimento de grãos de soja afetado pelo espaçamento entre linhas e fertilidade do solo. Ciência Rural, v.28, n.4, p.543-546, out-dez, 1998.

UDOGUCHI, A.; McCLOUND, D.E. Relationship between vegetative dry matter and yield of three soybean cultivars. Soil and Crop Science Society of Florida, Gainesville, v.46, p.75-79, out, 1987. 